\title{
PRÁTICA DO DUMPING SOCIAL NO PROJETO DE LEI N².330/2004 E A PRECARIZAÇÃO DAS RELAÇÕES E GARANTIAS TRABALHISTAS
}

\section{Lincoln Zub Dutra}

Advogado inscrito na OAB/PR 65.048. Graduado em Direito pela Universidade Católica do Paraná (PUC/ PR). Pós-graduado em Direito do Trabalho e Processo do Trabalho pela Pontifícia Universidade Católica do Paraná (PUC/PR). Mestre em Direitos Fundamentais e Democracia pelo Centro Universitário Autônomo do Brasil - Unibrasil. Professor universitário na Universidade Católica de Santa Catarina. Professor no Programa de Pós-Graduação da Universidade Católica de Santa Catarina. lincoln.zub@gmail.com

\section{Samuel Lima dos Santos}

Acadêmico de Direito pelo Instituto Superior do Litoral do Paraná - Isulpar. samucasantos@hotmail.com

Recebido em: 23/2/2016

Aceito em: 21/7/2017

\section{Resumo}

0 presente trabalho visa a abordar pelo viés jurídico e econômico a temática da presença do dumping social no projeto de lei no 4.330/2004 (que trata da terceirização das atividades-fim da empresa) e seus efeitos nas relações de trabalho e garantias trabalhistas, tema este de substancial relevância diante do futuro das relações do trabalho como conhecemos hoje. Para tanto será abordado num primeiro momento, de forma resumida, o conceito de dumping e sua origem nas relações de cunho econômico até a sua adoção no campo jurídico, perpassando também pela doutrina internacional que lhe deu origem com 0 conceito do punitive damages do Direito norte-americano, e mostrar alguns dos reflexos socioeconômicos presentes nas atividades overseas (exteriorização das atividades de empresas) para explicar as práticas de concorrência desleal que se apoiam na supressão de garantias mínimas do trabalhador, em detrimento da obtenção de lucro, utilizando mão de obra em países com legislação trabalhista precária ou inexistente. Passaremos até sua chegada na doutrina nacional e o processo de absorção e interiorização do dumping social utilizando a jurisprudência existente nos julgados até então. Por fim, se fará a análise do projeto de lei já mencionado e por meio da correlação entre o texto legal e os conceitos elencados, se buscará de forma conclusiva estabelecer os pontos de conflito entre o modelo de exploração do projeto de lei e as garantias tuteladas pelo Direito do Trabalho no ordenamento pátrio.

\section{Palavras-chave}

Legislação. Terceirização. Punitive damages. Dumping social. Garantias trabalhistas. 


\section{THE PRACTICE OF SOCIAL DUMPING IN DRAFT LAW № 4.330/2004 AND THE PRECARIFICATION OF WORK RELATIONS AND GUARANTEES}

\section{Abstract}

This study aims to address the legal and economic bias, the theme of the presence of social dumping in bill No. 4330/2004 (which deals with the outsourcing of core activities of the company) and its effects on labor relations and labor guarantees, theme this substantial relevance toward the future of labor relations as we know it today. For that will be addressed at first, briefly, the concept of dumping and its origin in the relations of economic developments to its adoption in the legal field, passing also by the international doctrine that gave rise to the concept of punitive damages from the north right -American, and show some of the socioeconomic reflexes in overseas activities (Externalization of the activities of companies) to explain unfair competitive practices that support the abolition of minimum guarantees of the worker, rather than making a profit using labor in countries with poor or non-existent labor laws. We pass over to his arrival in the national doctrine and the process of absorption and internalization of social dumping using existing case law of the courts so far. Finally, we will analyze the bill mentioned above and through the correlation between the legal text and listed concepts, it will seek to conclusively establish the points of conflict between the operating model of the bill and tutored guarantees by labor law on parental order.

\section{Keywords}

Legislation. Outsourcing. Punitive damages. Social dumping. Labor guarantees.

\section{Sumário}

1 Introdução. 2 Origem e Conceito do Dumping. 30 Punitive Damages e o Dumping Social. 4 Dumping Social nas Relações de Trabalho. 5 Breves Considerações Acerca da Terceirização e a Súmula 331 do TST. 60 Projeto de Lei № 4330/2004 e a Precarização das Relações Trabalhistas. 7 Conclusão. 8 Referências. 


\section{INTRODUÇÃO}

As relaçôes do homem com o trabalho em suas mais diversas formas remontam a tempos tão antigos que precisar o seu início é quase como buscar a gênese da própria humanidade. Essas relaçóes transmutaram-se com o desenvolvimento do ambiente que o cercava à medida que ele mesmo também o transformava desde o momento em que deixou de ser nômade e percebeu que poderia se estabelecer com os demais de seu convívio em um local específico e dali, por meio das habilidades adquiridas observando os organismos que o cercava, controlar o cultivo de plantas de acordo com a sazonalidade, capturar e domesticar pequenos animais para reprodução e posterior consumo, e para buscar aquilo que não tinha estabelecer com outros próximos às atividades de troca do produto de seu esforço até o advento da valoração de itens que vieram a representar valor monetário, como o sal e os metais. ${ }^{1}$

Do estabelecimento em aldeias até a organização em grandes civilizaçôes, existiu um fator chave para o controle da ordem social, que foi o surgimento do Direito, primeiro em sua forma natural decorrente do conhecimento elencado por esses agentes, e posteriormente a sua positivação até a sua chegada ao nosso contexto de civilização em sua vertente romano-germânica. ${ }^{2}$

A demasiadamente simplória introdução busca nos levar também a um evento específico iniciado há alguns séculos, que foi a Revolução Industrial, e a movimentação que levou a novos paradigmas da relaçáo patronal diante da vulnerabilidade do trabalhador nos centros urbanos, da segunda metade do século 20 partir do boom industrial das linhas de montagem que levou o Direito a uma profunda mudança em todos os seus ramos (entendendo aqui a divisão didática do Direito), e como desde então se busca proteger o trabalhador equacionando os pressupostos da dignidade do trabalho e deste como força motriz da Economia ${ }^{3}$ em relação aos seus efeitos no campo da Sociologia.

\footnotetext{
1 TOFFLER, Alvin. A terceira onda. Rio de Janeiro: Record, 1980. p. 27-45.

2 RÁO, Vicente. O direito e a vida dos direitos. São Paulo: Revista dos Tribunais, 2013. p. 140.

3 DELGADO, Mauricio Godinho. Curso de Direito do Trabalho. 15. ed. São Paulo: LTR, 2015, p. 387.
} 
Refletindo a partir destes eventos chave históricos, podemos nos situar e procurar entender de que forma a prática do dumping social encontra aí a sua correlação na fragilização das relaçôes trabalhistas ${ }^{4}$ no contexto atual com especial relevância no cenário brasileiro, sua interiorização e como o ordenamento jurídico e os magistrados têm tratado o tema.

O fator a considerar é o Projeto de Lei 4.330/2004 que visa a estabelecer novos parâmetros para a terceirização das atividades da empresa, ${ }^{5}$ e verificar como as relaçôes de trabalho e as garantias conquistadas ao longo dos anos podem vir a ser suprimidas com tal proposta, e demonstrar por meio deste trabalho quais pontos da relação trabalhista sofrerão maior precarização.

\section{ORIGEM E CONCEITO DO DUMPING}

Iniciando esta parte do estudo, analisemos o conceito de dumping em sua forma etimológica, segundo definição do verbete no dicionário de Cambridge:

$\mathrm{O}$ ato de livrar-se de algo que não é desejado (Trad.). ${ }^{6}$

O elencado supra mostra que a origem do dumping consiste na ação de livrar-se do não desejado, uma vez que aquilo não tem utilidade para si.

Outra fonte na qual nos basear diz respeito à aplicação do dumping no âmbito das relaçóes negociais, uma vez que consiste na prática de eliminar os demais atuantes do mesmo nicho de mercado em âmbito internacional por meio da prática de concorrência desleal com vistas a estrangular os meios de produção local inserindo-se no mercado estrangeiro pretendido.

Vieira (2002, p. 25), traz a seguinte definição:

4 SOUTO MAIOR, Jorge Luiz. Dumping social nas relaçôes de trabalho. 2. ed. São Paulo: LTR, 2014. p. 35.

5 Projeto de Lei 4330/2004 de autoria do Deputado Sandro Mabel do PL/GO, que dispóe sobre o contrato de serviço a terceiros e se propóe a regulamentar a terceirização no Brasil. Com sua emenda de $\mathrm{n}^{\circ} 15$ aprovado pela Câmara dos Deputados em 22 de abril de 2015.

${ }^{6}$ In verbis: the act of getting rid of something that is not wanted. Cambridge Advanced Learner's Dictionary. 4th edition. Cambridge-UK: Cambridge University Press, 2013. 
O dumping é a venda de produtos pelo preço de custo ou até mais baixo que seu preço de custo, buscando a ampliação de mercado. Essa prática é vista como desleal porque usa de meios ilegais para vencer a concorrência [...].

Sendo assim, o conceito do dumping econômico faz-se entender conforme se verifica o fenômeno da globalização industrial e da corrida pela oferta em mercados internacionais que vemos nos últimos 20 anos aproximadamente, porém esta é uma preocupação bem mais antiga, revelando-se muito difícil precisar seu início, pois já em 1904 o Canadá detinha leis ${ }^{7}$ com vistas a proteger seus interesses industriais das mesmas práticas que aqui tratamos, sem, contudo, outrora ser aplicado o conceito de dumping.

De forma a situar nosso estudo de acordo com a historicidade fática e documental, iniciamos após a Segunda Guerra Mundial devido à necessidade de reestruturação do cenário econômico mundial. Foram as tentativas do $\mathrm{FMI}^{8}$ e do BIRD $^{9}$ que deram origem à criação da Organização Internacional de Comércio (OIC), porém sem o sucesso esperado. Então surge o GATT ${ }^{10}$ em 1948 com 23 países signatários com o fulcro de ampliar a oferta de internacionalização das atividades industriais e entrada de produtos agindo como regulador das taxas de importação e exportação perante os participantes do acordo (dentre eles o Brasil).

$\mathrm{O}$ artigo VI do GATT tinha por objetivo evitar que medidas antidumping fossem tomadas de forma tão excessiva que viessem a prejudicar o livre-comércio entre as naçóes. ${ }^{11}$

7 Act to Amend the Customs Tariff, SC 1904.

8 (IMF - International Monetary Found) FMI - Fundo Monetário Internacional.- é uma organização internacional criada em 1944 na Conferência de Bretton Woods com o objetivo inicial de ajudar na reconstrução do sistema monetário internacional no período pós-Segunda Guerra Mundial. Disponível em: <http://www.imf.org/external/about.htm>. Acesso em: 20 out. 2015.

9 (IBRD - International Bank for Reconstruction and Development) Bird - Banco Internacional para Reconstrução e Desenvolvimento (Banco Mundial) é uma organização internacional que surgiu da Conferência de Bretton Woods (1944) para atender às necessidades de financiamento da reconstruçáo dos países devastados pela Segunda Guerra Mundial.

${ }^{10}$ GATT - General Agreement on Tariffs and Trades.

${ }^{11}$ Artigo VI, no 1, do GATT e artigo 2, no 1, do AARU (Rodada de Acordos do Uruguai). Disponível em: <http://www.desenvolvimento.gov.br/sitio/interna/interna.php?area=5\&menu=367>. Acesso em: 20 out. 2015. 
Conforme Boltuck:

Em virtude desta prática ser considerada injusta, o GATT permite que suas partes contratantes imponham medidas antidumping, nunca superiores à margem total de dumping (BOLTUCK, 1987, p. 53).

O GATT permaneceu por bom tempo regulando as atividades de comércio internacional, atuando como guardiāo das regras por meio de acordos firmados e disciplinando as práticas protecionistas das indústrias locais que barravam a entrada de competidores internacionais e subsidiando demasiadamente a produção local, o que foi de grande importância em vários países para estimular a oferta de produtos e forçar produtores internos a investirem em inovação tecnológica oferecendo produtos de melhor qualidade a preços competitivos. ${ }^{12}$

Em 1995 o GATT deu lugar à Organização Mundial de Comércio (OMC), que passou a agir da mesma forma disciplinando as relaçóes comerciais, com alcance muito mais amplo do que apenas o interesse econômico. Isso porque como órgáo vinculado à $\mathrm{ONU}$, a $\mathrm{OMC}$, em tese, busca equacionar o desenvolvimento econômico em países pobres, aliado às práticas de livre-comércio sem que haja sobreposição de interesses em detrimento da ONU, tampouco da OMC. ${ }^{13}$

A busca pela ampliação do lucro aliada à falta de ética e à fragilidade encontrada em muitas das legislaçóes locais, fez com que as oportunidades criadas pelo livre-comércio fossem transmutadas em práticas desleais de concorrência. A competitividade deu ensejo à justificação da prática sob a égide do suposto crescimento econômico.

$\mathrm{Na}$ busca por alcançar mercados internacionais distintos e enfrentar as empresas locais consolidadas, as indústrias começam a praticar preços muitas vezes abaixo até do custo de produção para entrar no referido mercado e com

${ }^{12}$ REGGO, Elba Cristina Lima. Do Gatt à OMC: O que mudou, como funciona e para onde caminha o sistema multilateral de comércio. Revista do BNDES no 6. Disponível em: <http://www.bndes.gov. br/SiteBNDES/bndes/bndes_pt/Institucional/Publicacoes/Conulta_Expressa/Tipo/Revista_do_BNDES/199612_6.html>. Acesso em: 23 out. 2015.

${ }^{13}$ DI SENA JÚNIOR, Roberto. Comércio internacional e globalização: a cláusula social na OMC. Curitiba: Juruá, 2003. 
isso enfraquecer os concorrentes locais, uma vez que náo conseguiam praticar os preços ofertados. Estes preços, contudo, só eram mantidos até que se eliminasse a concorrência, pois logo seriam seguidos de aumento e descaracterizados da possível prática de monopólio. ${ }^{14}$

Eis aqui o modelo de dumping em sua área de surgimento, o âmbito econômico das relaçóes negociais.

A fim de que não haja pontos divergentes destaca-se que para a prática do dumping deve estar latente a intenção de eliminação da concorrência mediante a aplicação das práticas desleais já mencionadas, não cabendo a confusão com a oferta de produtos em país estrangeiro a preço mais baixo obtido pelo emprego de novas tecnologias de materiais ou redução dos custos nos meios de produçáo sem detrimento das relaçóes patronais, pois este é o modelo de concorrência ética objetivado, mais uma vez em tese, pela OMC. ${ }^{15}$

Os avanços tecnológicos que possibilitaram a expansão da produção de riquezas, sem dúvida elevaram o comércio internacional a outro nível, mas em contrapartida possibilitaram que o lobby industrial alterasse a ordem jurídica ao longo dos anos, encontrando pontos fracos nos quais a ausência ou lentidão da evoluçáo jurídica diante das mudanças da sociedade propusesse o aumento exponencial dos efeitos da prática do dumping no que respeita a afetarem sobremaneira as relaçóes negociais e seus efeitos se estenderam para outros segmentos da sociedade com efeitos não só jurídicos, mas também sociológicos.

\section{PUNITIVE DAMAGES E 0 DUMPING SOCIAL}

$\mathrm{O}$ conceito punitive damages vem da experiência do common law norte-americano e corresponde ao seu antecessor, o exemplary damages britânico. ${ }^{16}$

\footnotetext{
${ }^{14}$ LEÂES, Luiz Gastão Paes de Barros. O “dumping” como forma de abuso do poder econômico. Revista de Direito Mercantil, Industrial, Econômico e Financeiro, São Paulo: Revista dos Tribunais, n. 91, p. 5-15, jul./set. 1993.

${ }^{15}$ BARROS, Maria Carolina Mendonça de. Antidumping e protecionismo. São Paulo: Aduaneiras, 2004. p. 35.

${ }^{16}$ STOCO, Rui. Tratado de responsabilidade civil: doutrina e jurisprudência. 8. ed. São Paulo: Ed. Revista dos Tribunais, 2011. p. 1.924.
} 
O caso britânico ${ }^{17}$ em tela foi de suma importância, pois decorreu de uma situação de excesso de poder político contra um cidadáo, conforme vemos no relato de Andrade:

O no 45 do jornal semanal The North Briton publicara artigo anônimo de conteúdo alegadamente ofensivo à reputação do rei George III e de seus ministros. Em consequência, Lord Halifax, secretário de Estado do rei, determinou a expedição de mandado genérico (general warrant), autorizando a prisão dos suspeitos de envolvimento na publicaçẫo do artigo, sem identificá-los nominalmente. Foram presas 49 pessoas, dentre as quais o autor do artigo, John Wilkes, inflamado membro da oposiçáo no Parlamento. Mensageiros do rei invadiram e reviraram a casa de Wilkes, forçando gavetas e apreendendo livros e papéis privados, sem inventariá-los. Wilkes, então, ajuizou uma action for trespass [ação de transgressão] contra Mr. Wood, subsecretário de Estado, que havia pessoalmente supervisionado a execuçáo do mandado. Demandou exemplary damages [indenização exemplar], ao argumento de que uma indenização de reduzido valor não seria suficiente para impedir a prática de condutas semelhante. $\mathrm{O}$ júri estabeleceu a soma, considerável para a época, de $£ 1000$ (mil libras) a título de punitive damages. ${ }^{18}$

A expressão punitive damages não encontra tradução literal na língua portuguesa, sendo traduzida livremente como "sançóes punitivas" que em nossa gramática pode incorrer em pleonasmo, posto que ambas têm significados idênticos, mas trataremos aqui das implicaçôes jurídicas e sociais desta prática nociva e deixaremos a questáo gramatical e semântica para o segmento competente.

Como vimos, mesmo tendo origem britânica, nos deteremos no sistema dos Estados Unidos da América, pois estes o desenvolveram com maior rigor científico a partir de 1996 aplicando-o de forma recorrente em seu ordenamento.

${ }^{17}$ English Court of Common Pleas. Wilkes v. Wood, 2 Wilson 203; 95 E.R. 766. Lofft 1; 98 E.R. 489, December 6, 1763.

${ }^{18}$ ANDRADE, André Gustavo Corrêa de. Dano moral e indenização punitiva: os punitive damages na experiência do comom law e na perspectiva do direito brasileiro. 2. ed. Rio de Janeiro: Lumen Juris, 2009. p. 179. 
O caso originário foi Gore vs BMW, ${ }^{19}$ que produziu toda uma sistemática que viria a ser aplicada depois em casos semelhantes. Na ocasiáo, o Dr. Ira Gore procurou uma revenda da BMW em janeiro de 1990 com o intuito de adquirir um veículo $0 \mathrm{Km}$. Concluído o negócio, cerca de oito meses depois Gore veio a fazer uma manutenção de rotina quando descobriu que a pintura de seu carro havia sido retocada. Como ele não havia realizado tal ação, identificou o "retoque" de pintura como originário na própria montadora. Após ajuizada a açáo contra a montadora argumentando falha no dever da informação, a BMW explicou que dede 1983 cerca de mil carros foram retocados após deixarem a linha de montagem e foram enviados para as revendas como carros novos, declarando que tal informação não era repassada para as revendas ou consumidores.

O Dr. Gore conseguiu provar que este ato desvalorizava o veículo em cerca de US\$ 4.000,00 (quatro mil dólares), valor que obteve como compensação ao final do julgado. Ainda assim o Juízo de Birminghan (Alabama Circuit Court) multiplicou esse valor pelo número de carros que sofreram o mesmo procedimento e estipulou o valor de US\$ 4.000.000,00 (quatro milhóes de dólares) para punitive damages. A montadora recorreu da decisão e a Corte Estadual do Alabama reduziu o valor para US\$2.000.000,00 (dois milhóes de dólares) por fatores que envolviam outros Estados da Federação.

A Suprema Corte Americana concedeu avocação ao processo e definiu três balizadores para os futuros casos envolvendo punitive damages, sendo eles: a) grau de repreensão de conduta; b) correspondência entre as sanções punitivas e o efetivo prejuízo produzido; c) magnitude de sançóes civis e criminais por condutas similares.

Este caso em particular teve repercussão nas relações de dumping social, uma vez que a montadora com o objetivo de auferir lucro desprezou o dever de informação ao consumidor, e o que se apurou foi o dano social gerado pela prática, pois não só o patrimônio de um indivíduo foi afetado, mas pela prática reiterada da supressão de direitos e cometimento de ilícito, toda a coletividade foi afetada.

${ }^{19}$ Supreme Court of The United States no 94-986 - BMW of North America, INC., PETITIONER, v. IRA GORE, Jr., May 20, 1996. 


\section{DUMPING SOCIAL NAS RELAÇÕES DO TRABALHO}

O Direito do Trabalho desempenha papel fundamental na relação patronal, à medida que busca proteger o trabalhador considerando este um ente em condição de hipossuficiência na relação jurídica em relação ao detentor dos meios de produção.

De forma filosófica, o caráter pragmático do Direito do Trabalho tem por escopo estabelecer direitos e deveres entre os atores das relaçóes, e abstém-se de estimular entre estes a dialética, tendo como objetivo sistêmico consolidar a segurança no mundo do trabalho alicerçando a pessoa a partir de garantias de esfera pública e participativa. ${ }^{20}$

Entre essas garantias é primaz a dignidade humana, que é preconizada na Constituição Federal de 1988 com valor supremo e norteador para a interpretação de todas as normas jurídicas. Esta mesma Constituição não define o conceito de dignidade e mesmo assim encontra-se nela uma carga axiológica que transcende sua limitação de norma.

Nas palavras de Lima Junior e Fermentão:

A primeira concepção de natureza jurídica da dignidade humana é que ela é uma norma jurídica e não se restringe a uma declaração ou postulado filosófico. Desta forma não é possível dizer que a dignidade humana possui apenas força declaratória ou uma norma abstrata sem significado jurídico.

Após a afirmativa de que a dignidade da pessoa humana é uma norma vem o questionamento: qual a natureza desta norma? Ela é uma regra ou um princípio? ${ }^{21}$

${ }^{20}$ ZENNI, Alessandro Severino Valler; PARRON, Stênio Ferreira. Por uma filosofia da pessoa no direito do trabalho. Revista Juridica Cesumar-Mestrado, v. 12, n. 1, p. 22, 2012.

${ }^{21}$ Lima Júnior, Paulo Gomes de; Fermentão, Cleide Aparecida Gomes Rodrigues. A eficácia do direito à dignidade da pessoa humana. Revista Jurídica Cesumar - Mestrado, v. 12, n. 1, p. 313-340, jan./ jun. 2012. 
Entre os, por assim dizer, elementos componentes da dignidade humana encontra-se o direito ao trabalho; este, por sua vez, reconhecido como direito social devido ao seu encontro convergente com o exercício pleno da cidadania. ${ }^{22}$

Segundo nos assevera o juiz Souto Maior, é importante que nos debrucemos na compreensão de que os direitos sociais são os frutos do compromisso firmado pela humanidade para que de forma concreta se pudesse construir justiça social dentro de uma sociedade capitalista. Estes mesmos direitos (Direito do Trabalho e Direito da Seguridade Social) foram firmados para compor o chamado capitalismo socialmente responsável. ${ }^{23}$

Tem-se em vista que à medida que estes direitos são atacados, seja de forma direta com a supressão de garantias trabalhistas nas atividades terceirizadas ou por "manobras jurídicas", é evidente que o dano causado e sua extensão atingem não só um núcleo mínimo, mas de forma conjunta outras esferas da vida em sociedade.

Mesmo com a conquista de garantias trabalhistas, nota-se que ainda existem no Brasil trabalhadores exercendo atividades degradantes, em condiçóes até mesmo de trabalho escravo. Importante frisar que este dito empregado, por sua fragilidade e necessidades primárias, busca tão somente manter o mínimo para a sobrevivência. A função que desempenha nestas condiçôes não pode ser considerada promotora da dignidade que apregoa a Constituição Federal. ${ }^{24}$

Afirma-se tal situação conforme argumente Souto Maior:

As terceirizações, subcontrataçôes, falências fraudulentas, táticas de fragilização do empregado (como falta de registro, transformaçấo do trabalhador em pessoa jurídica, dispensas sem pagamento de verbas rescisórias, justas causas fabricadas)

${ }^{22}$ BARBOSA JÚNIOR, José Raimundo; CABRERA, Rosangela de Paiva Leão. O dumping social na perspectiva atual da justiça do trabalho. Revista Objetiva, n. 8, 2012. Disponível em: <http:// revistaobjetiva.com/revista/wp-content/uploads/2013/02/O-DUMPING-SOCIAL-NA-PERSPECTIVA-ATUAL-DA-JUSTI\%C3\%87A-DO-TRABALHO-Jos\%C3\%A9-Raimundo-Barbosa-J\%C3\%BAnior-Ros\%C3\%A2ngela-de-Paiva-Le\%C3\%A3o-Cabrera-.pdf>. Acesso em: 20 out. 2015.

${ }^{23} \mathrm{O}$ capitalismo socialmente responsável não encontra definição conceitual acadêmica atualmente, $\mathrm{e}$ está inserido nos tópicos de Responsabilidade Social Corporativa do sistema norte-americano que visa a não preconizar exclusivamente o lucro em detrimento das relaçôes sociais, minimizando seus efeitos na sociedade de consumo. SOUTO MAIOR, Jorge Luiz. O dano social e sua reparaçấo. Revista $L T R$, vol. 71, n. 11, nov. 2007, p. 1.317.

${ }^{24}$ DELGADO, Mauricio Godinho. Curso de Direito do Trabalho. 15. ed. São Paulo: LTR, 2015. p. 200. 
têm imposto a milhóes de cidadãos brasileiros um enorme sacrifício quanto a seus direitos constitucionalmente consagrados, sendo que tal situaçáo tem, como visto, enorme repercussão no custo social (principalmente no que tange à seguridade social, à saúde e à educação) e no desenvolvimento econômico (diminuição do mercado interno), favorecendo, portanto, apenas às empresas multinacionais, ou seja, as que possuem capital estrangeiro, que produzem para o exterior, atendendo a propósitos monopolistas e com isso levando à falência as pequenas e médias empresas nacionais. ${ }^{25}$

Esses efeitos vêm, como já mencionado anteriormente, sob a égide de uma busca por competitividade, resultado do processo de globalização. Para isso invoca-se a crítica à rigidez do ordenamento jurídico brasileiro culminado com a excessiva carga tributária no produto final, o que leva a empresa a buscar alternativas para otimizar os lucros, atribuindo de forma errônea às garantias dos empregados a causa de uma suposta estagnação perante os mercados.

O dumping social é uma constante no Judiciário brasileiro, bastando para que se afirme o fato verificar o volume de ações judiciais em relação a mesma empregadora, com os mesmos pedidos de verbas trabalhistas mínimas e mesma causa de pedir. Tem-se a mesma figurando com certa frequência desrespeitando de forma contumaz as mesmas garantias. É papel do Estado, por meio do seu aparato judicial, conter estes abusos e os danos gerados. ${ }^{26}$

Neste contexto, importa destacar algumas decisóes recentes quanto à temática, senão vejamos:

17359391 - DUMPING SÓCIO-TABALHISTA. CONCEITO E APLICAÇÃO NO DIREITO DO TRABALHO. INDENIZAÇÃO PELO DANO SOCIAL DE NATUREZA SUPLEMENTAR EM PROL DO FAT- Dumping sócio-trabalhista é um termo utilizado para designar a prática empresarial visando à reduçáo dos custos da mão de obra, mediante o descumprimento reiterado da legislação. Segundo a doutrina de Jorge Luiz souto maior, a precarização completa

${ }^{25}$ SOUTO MAIOR, J. L.; MENDES, R.; SEVERO, V. S. Dumping social nas relaçóes de trabalho. São Paulo: LTR, 2012. p. 70.

${ }^{26}$ LOBATO JUNIOR, Fernando; PINTO, Cleidiane Martins. O combate ao Dumping Social no judiciário trabalhista brasileiro. Revista Amazônia em Foco, Castanhal, v. 2, n. 3, p. 44-64, jul./dez. 2013. 
das relaçóes sociais, decorrente das reiteradas agressóes aos direitos trabalhistas, traduz a prática de dumping social, apta a gerar um dano à sociedade, ato ilícito, por exercício abusivo do direito, já que extrapola limites econômicos e sociais, nos exatos termos dos artigos 186, 187 e 927 do Código Civil. Segundo esta doutrina, os fundamentos da reparação por dano social encontram- se no art. 404, parágrafo único do Código Civil, e artigos 652, d, e 832, $\$ 1^{\circ}$, da CLT. Nesse contexto, caracteriza-se o dumping quando a empresa obtém vantagens em decorrência da supressáo ou do descumprimento total ou parcial de direitos trabalhistas, reduzindo com essa postura o custo da produção, e potencializando maior lucro, o que, no fundo e em última análise, representa uma conduta desleal de prática comercial de preço predatório, além, é claro, da evidente violação aos direitos sociais. Esse importante tema foi objeto de estudo da $1^{a}$ jornada de direito material e processual na justiça do trabalho, realizada no final de 2007 , e desaguou no enunciado $n^{\circ} 4$, in verbis: Dumping social. Dano à sociedade. Indenização suplementar. As agressóes reincidentes e inescusáveis aos direitos trabalhistas geram um dano à sociedade, pois com tal prática desconsidera-se, propositalmente, a estrutura do estado social e do próprio modelo capitalista com a obtenção de vantagem indevida perante a concorrência. A prática, portanto, reflete o conhecido "dumping social", motivando a necessária reação do Judiciário trabalhista para corrigi-la. $\mathrm{O}$ dano à sociedade configura ato ilícito, por exercício abusivo do direito, já que extrapola limites econômicos e sociais, nos exatos termos dos arts. 186, 187 e 927 do Código Civil. Encontra-se no art. 404, parágrafo único, do Código Civil, o fundamento de ordem positiva para impingir ao agressor contumaz uma indenizaçáo suplementar, como, aliás, já previam os artigos 652, 'd', e 832, \$1º, da CLT. Assim, evidenciada a prática de dumping sócio-trabalhista, impóe-se a condenação da empresa ao pagamento de uma indenização suplementar em prol do Fat. (TRT 3 ${ }^{a}$ R.; RO 0010704-74.2014.5.03.0163; Rel. Des. Luiz Otávio Linhares Renault; DJEMG 27/02/2015; Pág. 48). ${ }^{27}$

22724538 - FRS S.A. AGRO AVÍCOLA INDUSTRIAL. JBS AVES LTDA. SUCESSÃO DIFERENCIADA. 1. As rés exploram a mesma atividade econômica no estabelecimento da prestação de serviços (Cnae 1012-1/01 abate de aves, suínos, bovinos e ovinos) e a ocorrência da locação da unidade industrial não autoriza a limitaçáo/exclusão de responsabilidades, considerando que a primeira ré continua no mesmo ramo de atividade (não foi extinta e nem alega

${ }^{27}$ TRT 3a Região - PROCESSO - RO 0010704-74.2014.5.03.0163 - Relator Desembargador Luiz Otávio Linhares Renault. Publicado no DJEMG em 27/02/2015. p. 48. 
tal situação) e também continua se beneficiando do labor prestado na fábrica locada, dela auferindo renda (aluguel). Ademais, o contrato entabulado entre as rés pode vir a ser rescindido por qualquer das signatárias a qualquer momento, caso em que a unidade retornará à administração da primeira demandada. 2 . Considerando o contexto peculiar do negócio operado entre as empresas demandadas, não cabe nenhuma limitação da responsabilidade, por se tratar de sucessão trabalhista sui generis. Muito embora tal instituto transfira a integralidade da responsabilidade ao sucessor, na espécie o estabelecimento empresarial continua de propriedade da demandada sucedida que opera o mesmo ramo de atividade da sucessora, podendo retomar as atividades a qualquer momento. 3. Cabível a responsabilizaçáo integral e solidária de ambas as rés quanto às obrigaçóes trabalhistas dos empregados da primeira demandada que prestaram serviços naquela unidade industrial. Eventuais controvérsias acerca da extensão das responsabilidades, decorrentes do contrato de locação da fábrica pactuado entre as mesmas, devem ser dirimidas no juízo cível. Inteligência dos arts. 10 e 448 da CLT. LESÃO MASSIVA DE DIREITOS SOCIAIS. DUMPING SOCIAL. CONDENAÇÃO DE OFÍCIO. A utilização do processo do trabalho, mediante a sonegação contumaz de direitos para posterior defesa em açáo trabalhista, com o afã de fragilizar as condições de trabalho, auferindo enriquecimento ilícito empresarial, com violação de dispositivos legais de ordem pública, sobretudo no que tange a direitos sociais consagrados na Constituiçáo da República, gera, sem dúvida, dano social, haja vista a flagrante violação dos preceitos do Estado Democrático de Direito concernentes à funçáo social da propriedade e aos valores sociais do trabalho e da livre iniciativa. Neste contexto, considerando a conduta reiterada das empresas rés, caracterizada pela supressão massiva de direitos trabalhistas, náo pode o julgador permanecer inerte diante deste quadro abusivo e nefasto que induz ao uso predatório do poder Judiciário. Condenação imposta de ofício no pagamento de indenização por dumping social. (TRT $4^{\mathrm{a}}$ R.; RO 0000704-74.2013.5.04.0663; Segunda Turma; Rel. Des. Marcelo José Ferlin D`Ambroso; DEJTRS 24/04/2015; Pág. 113). ${ }^{28}$

Com efeito, percebe-se de maneira clara e concisa a resposta dada pelo Judiciário à prática do dumping social, vez que além de gerar a denominada concorrência desleal no âmbito econômico, ofende, de maneira insofismável, garantias constitucionais tais como o direito à personalidade, à dignidade da pessoa humana, à valoração do trabalho, entre outros.

${ }^{28}$ TRT 4a Região - PROCESSO - RO 0000704-74.2013.5.04.0663 - Relator Desembargador Marcelo José Ferlin D’ Ambroso. Publicado no DEJTRS em 24/4/2015. p. 113. 
Como se vê, a noção de dano social já se encontra devidamente incorporada pela doutrina e jurisprudência ao Direito nacional, não sendo sequer questionada pela própria mídia não especializada, conforme se verifica na notícia vinculada em 24 de fevereiro de 2015, que trouxe à tona condenaçôes e sançôes sofridas por uma das maiores redes de fast-food do mundo, que em 2013 chegou a ser condenada pela Justiça de Pernambuco a pagar uma indenização de R \$ 7,5 milhões por dano moral coletivo. ${ }^{29}$

${ }^{29}$ Disponível em: <http://www.parana-online.com.br/editoria/economia/news/861381/?noticia=SIN DICATOS+DE+UNEM+CONTRA+REDE+DE+FAST+FOOD+MCDONALDS $>$. Acesso em: 24 fev. 2015. Sindicatos de unem contra rede de fast-food McDonald's. Publicaçáo24/2/2015 区 08h06Atualizado24/02/2015 $\otimes 09 \mathrm{~h} 41$. Um grupo de entidades sindicais, que tem o apoio da CUT e da UGT (Uniáo Nacional dos Trabalhadores), protocolou, nesta segunda-feira (23), na Justiça do Trabalho, em Brasília, uma ação civil pública contra a rede de fast-food McDonald's no Brasil, por violação de direitos trabalhistas.

Os sindicalistas acusam a Arcos Dorados, maior franqueadora do McDonald's na América Latina, de praticar "dumping social", por desrespeitar a legislação trabalhista com objetivo de reduzir custos e oferecer preços mais competitivos que os da concorrência. E pedem que a rede fique proibida de abrir novas unidades caso continue a cometer irregularidades.

A ofensiva dos sindicatos brasileiros ocorre num momento em que a matriz americana vem sendo pressionada por ativistas a aumentar a remuneração de seus funcionários e seguir o exemplo de grandes varejistas, como o Walmart, que decidiram pagar mais que o salário mínimo vigente nos Estados Unidos. Com o apoio informal da americana União Internacional dos Empregados em Serviços (Seiu, na sigla em inglês), a ação movida contra a rede de fast-food, que emprega quase 48 mil pessoas no Brasil, vai além da questấo salarial e incluiu acusaçôes de acúmulo e desvio de funçôes; fraude nos controles de ponto; não recolhimento do FGTS e prática de "jornada móvel de trabalho", em que o empregado fica mais de oito horas à disposição da empresa. Em nota, a assessoria de imprensa do McDonald's informou apenas que a empresa ainda náo foi notificada.

Processos

Entre 2012 e agosto de 2014, as entidades sindicais levantaram cerca de 400 processos trabalhistas contra a multinacional no país inteiro. Essa pesquisa foi feita por amostragem, o que significa que o número pode ser bem superior a esse.

De lá para cá, o McDonald's chegou a assinar termos de ajustamento de conduta com trabalhadores, com o Ministério Público do Trabalho e com a própria Justiça, mas, com base no levantamento, os sindicalistas afirmam que as irregularidades não foram corrigidas.

"Essa empresa vem violando os acordos de forma sistemática, desrespeitando a legislação brasileira e a dignidade do trabalhador", diz Moacyr Roberto Tesch Auersvald, presidente da Confederaçáo Nacional dos Trabalhadores em Turismo e Hospitalidade (Contratuh), que é a entidade autora da ação junto com o Sinthoresp, representante dos funcionários de fast-food em São Paulo. "Diferentes níveis de entidades sindicais decidiram se unir porque o descumprimento das regras trabalhistas ocorre em todo o território nacional", diz Antônio Carlos Lacerda, coordenador jurídico do Sinthoresp.

Essa é a primeira mobilização nacional contra a rede de fast-food no país, mas, regionalmente, a empresa já vem enfrentando processos. O mais emblemático terminou em março de 2013 com a decisão da Justiça de Pernambuco que obrigou a rede a pagar uma indenizaçáo de $\mathrm{R} \$ 7,5$ milhóes por dano moral coletivo. A empresa foi acionada, na ocasião, por obrigar funcionários a fazer a jornada móvel e consumir apenas lanches do McDonald's no horário das refeiçóes.

Agora, os sindicatos pedem, liminarmente, que a Justiça dê um prazo para que a rede corrija as irregularidades sob pena de ficar proibida de abrir novas unidades no país. No processo conjunto em que acusa o McDonald's de "dumping social", os trabalhadores também pedem ressarcimento por dano moral e pagamento de indenização, em valores que podem variar de $1 \%$ a $30 \%$ do faturamento da companhia. As informaçóes são do jornal O Estado de S. Paulo. 
O Judiciário nacional encontra ferramental para lidar com as situaçóes de dano causadas pela prática do dumping social na ordem econômica e no âmbito trabalhista, ao contrário do que bradam juristas conservadores e convenientemente parte dos advogados corporativos.

$\mathrm{O}$ artigo 170 da Constituição traz de forma expressa a finalidade da ordem econômica e os seus pilares de suporte com fulcro no respeito aos ditames da justiça social aplicada na totalidade dos cidadãos. ${ }^{30}$

$\mathrm{O}$ artigo 20, Inciso I, da Lei n. 8.844/94, ${ }^{31}$ mostra que à medida que o dumping social gera concorrência imperfeita, fraudulenta, é passível de punição prevista no artigo 23 , inciso $\mathrm{I}^{32}$ da mesma lei.

Também o Código Civil, por meio de uma leitura constitucionalizada, traz no artigo 421 e $\$ 1^{\circ}$ do artigo 1.228 a função social do contrato, o que revela a preocupação do legislador em resguardar os princípios da Carta Magna.

De suma importância é o Enunciado n. 4, aprovado pela Anamatra ${ }^{33}$ e pelo TST: ${ }^{34}$

\section{DUMPING SOCIAL. DANO À SOCIEDADE. INDENIZAÇÃO SUPLE-}

MENTAR. As agressóes reincidentes e inescusáveis aos direitos trabalhistas geram um dano à sociedade, pois com tal prática desconsidera-se, propositalmente, a estrutura do Estado social e do próprio modelo capitalista com a obtenção de vantagem indevida perante a concorrência. A prática, portanto, reflete o conhecido "dumping social", motivando a necessária reação do Judiciário trabalhista para corrigi-la. O dano à sociedade configura ato ilícito, por exercício abusivo

\footnotetext{
30 "Art. 170: a ordem econômica, fundada na valorizaçáo do trabalho humano e na livre iniciativa, tem por fim assegurar a todos existência digna, conforme os ditames da justiça social."

31 "Art. 20. Constituem infração da ordem econômica, independentemente de culpa, os atos sob qualquer forma manifestados, que tenham por objeto ou possam produzir os seguintes efeitos, ainda que não sejam alcançados:

I - limitar, falsear ou de qualquer forma prejudicar a livre concorrência ou a livre-iniciativa;"

32 "Art. 23. A prática de infraçấo da ordem econômica sujeita os responsáveis às seguintes penas:

I - no caso de empresa, multa de um a trinta por cento do valor do faturamento bruto no seu último exercício, excluídos os impostos, a qual nunca será inferior à vantagem auferida, quando quantificável;"

${ }^{33}$ Associação Nacional dos Magistrados Trabalhistas.

${ }^{34}$ Tribunal Superior do Trabalho.
} 
do direito, já que extrapola limites econômicos e sociais, nos exatos termos dos arts. 186, 187 e 927 do Código Civil. Encontra-se no art. 404, parágrafo único do Código Civil, o fundamento de ordem positiva para impingir ao agressor contumaz uma indenização suplementar, como, aliás, já previam os artigos 652, “d”, e832, \$1º, da CLT. (JORNADA DE DIREITO MATERIAL E PROCESSUAL, 21-23 nov. 2007. Brasília)

A doutrina civilista expóe acerca do dano toda retração dos bens jurídicos de um indivíduo em razão de atos ilícitos praticados por terceiros ${ }^{35}$.

Sendo assim, é possível demonstrar de forma clara o dano moral sofrido pelo trabalhador como pessoa, diferenciando do dano patrimonial também ocasionado, permitindo que também se utilize o instituto do dano moral presente no artigo $5^{\circ}$, incisos $\mathrm{V}$ e X.

A título de punição às empresas, tem-se aplicado não só as decisóes pela condenação, mas indenização suplementar na maioria dos casos, uma vez que não é possível mensurar as extensóes do dano na sociedade. Tal penalidade tem a finalidade de desestimular a repetição da prática e compensar, ainda que parcialmente, o benefício econômico já obtido e encontra fundamento no instituto do fluid recovery ${ }^{36}$ do ordenamento norte-americano.

${ }^{35}$ SARMENTO, George. Danos morais. Coordenação Edison Mougenot Bonfim. 1. ed. São Paulo: Saraiva, 2009. p. 90. (Coleção prática de direito, v. 9).

${ }^{36}$ No aspecto da reparação, o tema em questão atrai a aplicação do provimento jurisdicional denominado na experiência americana de fluid recovery ou ressarcimento fluído ou global, quando o juiz condena o réu de forma que também o dano coletivo seja reparado, ainda que não se saiba quantos e quais foram os prejudicados e mesmo tendo sido a ação intentada por um único indivíduo que alegue o próprio prejuízo. (SOUTO MAIOR; SANTOS; SEVERO, 2012, p. 6). 


\section{BREVES CONSIDERAÇÕES ACERCA DA TERCEIRIZAÇÃO E A SÚMULA 331 DO TST}

A prática de terceirizar as atividades-fim da empresa surge durante a Segunda Guerra Mundial, devido à aliança norte-americana com os países europeus para o combate ao nazismo e Japão, o que ocasionou uma corrida da indústria bélica por pessoal para suprir a demanda excessiva recém-criada. ${ }^{37}$

Com a união de esforços entre as empresas de material bélico e os militares, verificou-se que era possível produzir de forma mais precisa, com redução de custos, e de certa forma equilibrando o mercado de trabalho prejudicado pelo conflito com a utilização da oferta abundante de mão de obra, o que à época foi considerado uma boia de salvaçáo.

No início dos anos 50 houve uma significativa mudança no planejamento estratégico das empresas. As indústrias automobilísticas foram as maiores fomentadoras da terceirização, principalmente a Ford, com o sistema de outsourcing, ${ }^{38}$ adquirindo componentes de terceiros, e, por conseguinte reduzindo custos de produção (edificaçóes, máquinas, equipamentos e pessoal). ${ }^{39}$ Tais componentes eram obtidos por meio de fornecedores sem ligação empregatícia com a fábrica, e por vezes em parceria com outras montadoras para que as peças fossem fabricadas em larga escala, reduzindo de maneira substancial seu preço.

${ }^{37}$ CASTRO, Rubens Ferreira de. A terceirização no direito do trabalho. São Paulo: Malheiros, 2000. p. 75.

${ }^{38}$ In verbis: $\mathrm{O}$ outsourcing é uma expressão inglesa normalmente traduzida para o português como "terceirização". No mundo dos negócios, o outsourcing é um processo usado por uma empresa no qual outra organização é contratada para desenvolver uma certa área da empresa. PEREIRA, Maria Isabel; FERREIRA, Ademir Antonio; REIS, Ana Carla Fonseca. Gestão empresarial: de Taylor aos nossos dias. 1. ed. São Paulo: Pioneira, 2001. p. 98.

${ }^{39}$ Femenick, Tomislav R. fordismo, toyotismo e verticalização. Disponível em: <http://www.tomislav. com.br/fordismo-toyotismo-e-verticalizacao/>. Acesso em: 20 out. /2015. 
Desta prática nasceram os conceitos de downsizing, ${ }^{40}$ como legado administrativo que visava a aplicar os conceitos de logística a todos os setores produtivos das fábricas". ${ }^{41}$

No caso específico do Brasil, as primeiras formas de trabalho temporário foram a "empreitada" e a "subempreitada", previstas no artigo 455 da CLT de 1943 , porém ganharam relevância no decorrer dos últimos 30 anos, a partir da Lei 6.019/74, conforme expóe Delgado (2015):

A regulação normativa da terceirização no mercado privado, ocorreu, inicialmente, através de dois modelos restritos de contratação: o trabalho temporário (lei 6.019/74) e o trabalho de vigilância bancária (lei 7.102/83).42

A própria lei 6.019/74 define o trabalho temporário:

Art. $2^{\circ}$ - Trabalho temporário é aquele prestado por pessoa física a uma empresa, para atender à necessidade transitória de substituição de seu pessoal regular e permanente ou a acréscimo extraordinário de serviços.

Mesmo admitindo o trabalho temporário em decorrência de um período marcado pelo desemprego e instabilidade econômica, ambos os dispositivos legais (lei 6.019/74 e a CLT) trataram de delimitar as atividades dos trabalhadores por eles tutelados. $\mathrm{O}$ trabalhador admitido a prazo na CLT, mesmo que por curto período de tempo, tem relação direta com o empregador e pode ser considerado "empregado clássico", enquanto o trabalhador temporário, pela lei 6.019/74, tem contrato com a empresa de trabalho temporário e não com o destinatário final dos serviços a serem prestados. ${ }^{43}$

\footnotetext{
${ }^{40}$ In verbis: $\mathrm{O}$ downsizing, que em português significa "achatamento", é uma técnica conhecida em todo o mundo e que visa a eliminação de processos desnecessários que engessam a empresa e atrapalham a tomada de decisáo, com o objetivo de criar uma organização mais eficiente e enxuta possível. PEREIRA, Maria Isabel; FERREIRA, Ademir Antonio; REIS, Ana Carla Fonseca. Gestão empresarial: de Taylor aos nossos dias. 1. ed. Sáo Paulo: Pioneira, 2001. p. 98.

${ }^{41}$ CAVALCANTI, Ophir Junior. A terceirização das relações laborais. São Paulo: LTR, 2007. p. 20.

42 DELGADO, Mauricio Godinho. Curso de Direito do Trabalho. 15. ed. São Paulo: LTR, 2015. p. 435.

${ }^{43}$ Ibidem, p. 452.
} 
Até recentemente, antes da sanção do PL N.4.330/2004, vislumbrava-se neste mesmo patamar a Súmula 331 que regulava a terceirização no Brasil. Tal dispositivo visava a balizar as atividades de terceirização lícita no país. De forma resumida a mesma dispunha de quatro itens, mas em 2011 o TST alterou a Súmula 331 para suma, para não aplicar responsabilidade subsidiária automática à Administraçáo Pública em decorrência do inadimplemento de obrigaçóes trabalhistas do empregador e impossibilidade de geração de vínculo no trabalho temporário, vigilância e conservação. ${ }^{44}$

Entre as muitas críticas possíveis de serem delineadas, vê-se que as atividades "resguardadas" pela alteração são as mesmas que o poder público se utiliza em larga escala na terceirização, e não é em vão que é um dos maiores demandados ante o poder Judiciário, incorrendo até mesmo em açôes que objetivam o estabelecimento de vínculo empregatício, o que já foi assentado de forma negativa em razão da previsão constitucional de concurso para o ingresso no serviço público.

Dessa forma verificaremos que ao avançarmos no tema proposto, vimos de que forma as relaçôes de trabalho foram se transmutando e avançando em razão das demandas sociais. É importante frisar que a análise aqui busca demonstrar que o modelo de terceirização trazido no referido projeto de lei rompe de forma abrupta as garantias trabalhistas e o vínculo empregado-empresa, implicando um negativo efeito cascata.

\section{PROJETO DE LEI N.330/2004 E A PRECARIZAÇÃO DAS RELAÇÕES E GARANTIAS TRABALHISTAS}

Alvo de grande polêmica, o projeto de lei 4.330/2014 vem demarcar novos patamares na terceirização de atividades da empresa. Isso deve-se à possibilidade de terceirizar "qualquer" atividade da empresa, mesmo ela sendo a atividade-fim.

Em 7 de agosto de 2013 o juiz do trabalho Jorge Luiz Souto Maior já demonstrava preocupação com o tema na carta intitulada: "PL4.330 O Shopping Center Fabril", carta esta que replicou em 6 de abril de 2015 com o título "PL

${ }^{44}$ MARTINS, Sergio Pinto. Comentários às Súmulas do TST. 14. ed. São Paulo: Atlas, 2014. p. 122. 
4.330/04: maldade explícita e ilusão", ${ }^{45}$ o qual assevera que o projeto traz em si argumentos que levam o trabalhador a crer que a terceirização se converte em algo benéfico para este enquanto tendência para a sobrevivência das empresas no Brasil.

Acertada observação encontra-se neste texto quando aponta para a contradição encontrada na exposição de motivos do dispositivo referente quando explicita: "Nesse contexto, a terceirização é uma das técnicas de administração do trabalho que têm maior crescimento, tendo em vista a necessidade que a empresa moderna tem de concentrar-se em seu negócio principal e na melhoria da qualidade do produto ou da prestação de serviço" (grifo nosso).

Dessa forma, o mesmo nos traz a seguinte explanaçáo acerca deste modelo de terceirização:

\begin{abstract}
A terceirização, ainda, visa a dificultar que se atinja a necessária responsabilidade social do capital. Nesse modelo de produção, a grande empresa não contrata empregados, contrata contratantes e estes, uma vez contratados, ou contratam trabalhadores dentro de uma perspectiva temporária, não permitindo sequer a formação de um vínculo jurídico que possa ter alguma evoluçáo, ou contratam outros contratantes, instaurando-se uma rede de subcontrataçóes que provoca, na essência, uma desvinculação física e jurídica entre o capital e o trabalho, tornando mais difícil a efetivação dos direitos trabalhistas, pois o empregador aparente, aquele que se apresenta de forma imediata na relação com o trabalho, é, quase sempre, desprovido de capacidade econômica ou, ao menos, possui um capital bastante reduzido se comparado com aquele da empresa que o contratou. ${ }^{46}$
\end{abstract}

Há que se observar que se o referido projeto traz em seu escopo que qualquer atividade pode ser objeto de terceirização, ${ }^{47}$ resta concluir que o "lucro" é o objetivo principal, descaracterizando assim os princípios sociais já elencados no início deste trabalho.

45 SOUTO MAIOR, Jorge Luiz. PL 4.330/04: maldade explícita e ilusăo. Disponível em: <http://blogdaboitempo.com.br/2015/04/06/pl-4-33094-maldade-explicita-e-ilusao >. Acesso em: 5 nov. 2015.

${ }^{46}$ SOUTO MAIOR, Jorge Luiz. PL 4.330/04: maldade explícita e ilusão. Disponível em: <http://blogdaboitempo.com.br/2015/04/06/pl-4-33094-maldade-explicita-e-ilusao>. Acesso em: 5 nov. 2015.

${ }^{47}$ PL 4330/2004 - artigo 40 caput - "É lícito o contrato de terceirização relacionado a parcela de qualquer atividade da contratante que obedeça aos requisitos previstos nesta Lei, não se configurando vínculo de emprego entre a contratante e os empregados da contratada, exceto se verificados os requisitos previstos nos arts. $2^{\circ}$ e $3^{\circ}$ da Consolidação das Leis do Trabalho - CLT, aprovada pelo Decreto-Lei $\mathrm{n}^{\circ} 5.452$, de $1^{\circ}$ de maio de 1943 ". 
Para Renato Saraiva, procurador do Trabalho na Procuradoria Regional do Trabalho - 6a Região (PRT6):

De fato, a regulamentação da terceirização é necessária e tem seus benefícios. As empresas contratantes ganham mais segurança jurídica, afastando possíveis processos trabalhistas e ampliando o poder de investimento e geração de emprego. A legislação vigente já não atende mais às práticas modernas de produção, e a flexibilidade dos contratos terceirizados supre essa carência. A regulamentação ainda induz à criação de novas empresas especializadas, iguala as condições empresariais à tendência mundial da terceirização, e estimula a responsabilidade social com a maior exigência de fiscalização. Todavia, não obstante as manifestaçóes favoráveis ao Projeto de Lei no 4.330/2004, somos totalmente contrários à terceirização indiscriminada e generalizada proposta pelo projeto, que, se aprovado e transformado em lei, representará um retrocesso na garantia dos direitos sociais da classe trabalhadora desse país. ${ }^{48}$

Nesse sentido urge destacar que preocupados com os reflexos sociais do projeto em várias esferas e o andamento da Justiça do Trabalho, 19 dos 26 ministros do TST foram signatários de carta aberta em 27 de agosto de 2013, endereçada ao deputado Décio Lima, então presidente da Comissão de Constituição e Justiça e de Cidadania, carta esta que destaca pontos tangiveis na relação patronal, com especial destaque ao ponto no 3 :

[...] III. A diretriz acolhida pelo PL no 4.330-A/2004, ao permitir a generalização da terceirização para toda a economia e a sociedade, certamente provocará gravíssima lesão social de direitos sociais, trabalhistas e previdenciários no país, com a potencialidade de provocar a migração massiva de milhões de trabalhadores hoje enquadrados como efetivos das empresas e instituiçóes tomadoras de serviços em direção a um novo enquadramento, como trabalhadores terceirizados, deflagrando impressionante redução de valores, direitos e garantias trabalhistas e sociais.

${ }^{48}$ SARAIVA, Renato. Veja como a lei da terceirização vai mudar a vida do trabalhador. Disponível em: <http://economia.ig.com.br/2015-04-09/veja-como-a-lei-da-terceirizacao-vai-mudar-a-vida-do-trabalhador.html>. 
Neste sentido, o Projeto de Lei esvazia o conceito constitucional e legal de categoria, permitindo transformar a grande maioria de trabalhadores simplesmente em "prestadores de serviços" e não mais "bancários", "metalúrgicos", "comerciários", etc.

Como se sabe que os direitos e garantias dos trabalhadores terceirizados são manifestamente inferiores aos dos empregados efetivos, principalmente pelos níveis de remuneração e contratação significativamente mais modestos, o resultado será o profundo e rápido rebaixamento do valor social do trabalho na vida econômica e social brasileira, envolvendo potencialmente milhóes de pessoas. ${ }^{49}$

Em sua página de conteúdo acadêmico em uma rede social, a jurista Vólia Bomfim Cassar expôs a expansão de casos de terceirização para as atividades principais (atividade-fim), afirmando que tal medida cria mais empregos e reduz a informalidade, e que "o objetivo do projeto é a redução do custo da mão de obra com a reduçáo do valor do salário, pois não será mais necessário respeitar o piso normativo, apenas o legal, e permitir a supressáo de antigas conquistas da categoria, como os benefícios previstos nas convenções e acordos coletivos". ${ }^{50}$

Entre os principais malefícios do projeto encontra-se uma tendência de ampliar o quadro de terceirizados no Brasil, pois dispondo de um suporte legal para fazê-lo e vislumbrando uma possibilidade de aumentar os lucros com certeza buscará o empresariado a "porta larga", descartando seus efeitos numa ordem material e moral.

Verifica-se que a preocupação com o projeto é legítima e não constitui um discurso falacioso. Prova disso fazemos trazendo à luz os fatos a que estáo expostos os trabalhadores terceirizados com a referida proposta:

a) o salário pago aos terceirizados é em média $24 \%$ menor do que os empregados contratados diretamente; b) os trabalhadores terceirizados trabalham, em média, três horas a mais por semana do que os contratados diretamente; c) os terceirizados são os empregados que mais sofrem acidentes. Na Petrobras,

\footnotetext{
${ }^{49}$ Disponível em: <http://www.conjur.com.br/2013-set-03/maioria-ministros-tst-condena-pl-libera-terceirizacao >. Acesso em: 5 out. 2015.

${ }^{50}$ Disponível em: <https://www.facebook.com/permalink.php?story_fbid=684622208314566\& $\mathrm{id}=170496876393771>$. Acesso em: 5 out. 2015.
} 
mais de $80 \%$ dos mortos em serviço entre 1995 e 2013 eram subcontratados; d) Segundo ministros do TST, os trabalhadores terceirizados são vítimas de acidentes de trabalho e doenças ocupacionais com maior frequência, o que gera gastos ao setor público, pois os mesmos só podem recorrer ao SUS; e) maior ocorrência de denúncias de discriminação está em setores onde há mais terceirizados, como os de limpeza e vigilância, segundo relatório da Central Única dos Trabalhadores (CUT); f) terceirizados que trabalham em um mesmo local têm patrōes diferentes e são representados por sindicatos de setores distintos. Essa divisão afeta a capacidade deles pressionarem por benefícios; g) entre 2010 e 2014, cerca de $90 \%$ dos trabalhadores resgatados nos dez maiores flagrantes de trabalho escravo contemporâneo eram terceirizados, conforme dados do Ministério do Trabalho e Emprego. Casos como esses já acontecem em setores como mineração, confecções e manutenção elétrica; h) toda empresa com 100 ou mais empregados reserve de $2 \%$ a $5 \%$, dependendo do total de funcionários, das vagas para pessoas com deficiência. Com a possibilidade de terceirização de todas as atividades, incluindo as finalísticas, as companhias podem não alcançar esse número mínimo de trabalhadores e, dessa forma, não terão obrigação de contratar o percentual definido por lei; ${ }^{51}$

Até aqui que se buscou procurar a posição doutrinária acerca do tema por meio de doutrinadores atuantes na Justiça do Trabalho e que desempenham papel transformador nas relaçóes sociais afetas por este ramo do Direito e consegue-se verificar de forma clara que os malefícios estão latentes tanto no seu projeto quanto no seu discurso.

\section{CONCLUSÃO}

Pelo que foi até aqui elencado, vimos que num cunho histórico foi possível acompanhar a ascensão das garantias trabalhistas em consonância com as demandas sociais, como a Constituição Federal foi o marco de garantia do mínimo existencial preconizando à dignidade humana como norte para o desenvolvimento das rela-

${ }^{51}$ SARAIVA, Renato. Lei da terceirização: posição contrária. Jornal Carta Forense, 2 jun. 2015. Disponível em: <http://cartaforense.com.br/conteudo/artigos/lei-da-terceirizacao--posicao-contraria/15392>. Acesso em: 6 nov. 2015. 
çôes trabalhistas, definindo também uma leitura da função social e da dimensão transformadora da sociedade que o trabalho tem, sendo ele o esteio da economia, produtor primário de riqueza e transformador do homem.

O projeto de lei não encontra apoio senão no empresariado que sufoca a relaçáo mais frágil do trabalho; por vislumbrar um grande número de pessoas "disponíveis" no mercado fez-se da força de trabalho mercadoria barata que despersonaliza seu executor relegando-o à categoria de "coisa", sendo possível substituí-lo "sem defeito aparente".

Ao findar a relação frustrada de trabalho numa terceirização ou quarteirização, o mesmo não encontra apoio daquele que diretamente usufruiu de sua força de trabalho, ficando sem direção.

Estará no meio de muitos, mas não pertencerá a lugar algum, trazendo consigo sentimento de insegurança pela falta do vínculo.

A isonomia não se fará presente, visto que não será possível ser igual aos demais que no mesmo local desempenham sua função pela empresa. Nesse caso só se vislumbra a isonomia com aqueles que se encontram na mesma situação de precarização.

Descartada a pretensão de esgotar aqui tema de tamanha complexidade, finda-se este trabalho trazendo à luz da reflexão seu tema de destaque: Há ou não a presença do dumping social no PL nº4.330/2004?

Pelo que já foi elencado salta aos olhos que a empresa cometerá o dumping social em sua forma mais "cristalina", subjugar as garantias trabalhistas em nome do lucro, porém o que é de se espantar é que o próprio projeto de lei permitirá que isso aconteça com o aval que a segurança jurídica do ordenamento pátrio permite!

As necessidades de competitividade apresentadas pelos que representam o mundo corporativo podem encontrar soluçôes viáveis sem que se afete de forma abrupta todo um sistema de garantias construído ao longo de anos nos quais foi necessário proteger o trabalhador, e ainda o é, sob pena de a curto prazo promover ainda mais a desvalorizaçáo da mão de obra. 


\section{REFERÊNCIAS}

ANDRADE, André Gustavo Corrêa de. Dano moral e indenização punitiva: os punitive damages na experiência do comom law e na perspectiva do direito brasileiro. 2. ed. Rio de Janeiro: Lumen Juris, 2009.

BARBOSA JÚNIOR, José Raimundo; CABRERA, Rosangela de Paiva Leão. O dumping social na perspectiva atual da justiça do trabalho. Revista Objetiva, n. 8, 2012. Disponível em: <http://revistaobjetiva.com/revista/wp-content/uploads/2013/02/O-DUMPING-SOCIAL-NA-PERSPECTIVA-ATUAL-DA-JUSTI\%C3\%87A-DO-TRABALHO-Jos\%C3\%A9-Raimundo-Barbosa-J\%C3\%BAnior-Ros\%C3\%A2ngela-de-Paiva-Le\%C3\%A3o-Cabrera-. pdf>. Acesso em: 20 out. 2015.

BARROS, Maria Carolina Mendonça de. Antidumping e protecionismo. São Paulo: Aduaneiras, 2004.

BOLTUCK, Richard D. An economic analysis of dumping. Journal of World Trade Law, Twickenham, v. 21, n. 5, p. 45-54, out. 1987. Disponível em: <http://www.kluwerlawonline. com/abstract.php?area=Journals\&id=TRAD1987041>. Acesso em: 20 out. 2015.

CAMBRIDGE ADVANCED LEARNER'S DICTIONARY. $4^{\text {th }}$ edition. Cambridge-UK: Cambridge University Press, 2013.

CASTRO, Rubens Ferreira de. A terceirização no direito do trabalho. São Paulo: Malheiros, 2000. p. 75 .

CAVALCANTI, Ophir Junior. A terceirização das relações laborais. São Paulo: LTr, 2007. p. 20.

DELGADO, Maurício Godinho. Curso de Direito do Trabalho. 10. ed. São Paulo: LTR, 2011.

DELGADO, Maurício Godinho. Curso de Direito do Trabalho. 15. ed. São Paulo: LTR, 2015. p. 387, 435 .

SOUTO MAIOR, Jorge Luiz. Dumping social nas relações de trabalho. 2. ed. São Paulo: LTR, 2014. p. 35.

DI SENA JÚNIOR, Roberto. Comércio internacional e globalização: a cláusula social na OMC. Curitiba: Juruá, 2003.

FEMENICK, Tomislav R. fordismo, toyotismo e verticalização. Disponível em: <http:// www.tomislav.com.br/fordismo-toyotismo-e-verticalizacao/>. Acesso em: 20 out. 2015. 
LEÃES, Luiz Gastão Paes de Barros. O “dumping” como forma de abuso do poder econômico. Revista de Direito Mercantil, Industrial, Econômico e Financeiro, São Paulo: Revista dos Tribunais, n. 91, p. 5-15, jul./set. 1993.

LIMA JÚNIOR, Paulo Gomes de; FERMENTÃO, Cleide Aparecida Gomes Rodrigues. A eficácia do Direito à dignidade da pessoa humana. Revista Juridica Cesumar-Mestrado, v. 12, n. 1, p. 313-340, jan./jun. 2012.

LOBATO JUNIOR, Fernando; PINTO, Cleidiane Martins. O combate ao dumping social no Judiciário trabalhista brasileiro. Revista Amazônia em Foco, Castanhal, v. 2, n. 3, p. 4464, jul./dez. 2013.

MARTINS, Sergio Pinto. Comentários às Súmulas do TST. 14. ed. São Paulo: Atlas, 2014. p. 122 .

PEREIRA, Maria Isabel; FERREIRA, Ademir Antonio; REIS, Ana Carla Fonseca. Gestão empresarial: de Taylor aos nossos dias. 1. ed. São Paulo: Pioneira, 2001. p. 98.

RÁO, Vicente. O direito e a vida dos direitos. São Paulo: Revista dos Tribunais, 2013.p. 140.

RÊGO, Elba Cristina Lima. Revista do BNDES no 06. Do Gatt à OMC: o que mudou, como funciona e para onde caminha o sistema multilateral de comércio. Disponível em: <http:// www.bndes.gov.br/SiteBNDES/bndes/bndes_pt/Institucional/Publicacoes/Conulta_Expressa/Tipo/Revista_do_BNDES/199612_6.html>. Acesso em: 23 out. 2015.

RODRIGUES, José Roberto Pernomian. O dumping como forma de expressão do abuso do poder econômico: caracterizaçáo e conseqüências. 1999. Tese (Doutorado) - Faculdade de Direito da Universidade de São Paulo, 1999, 284 p.

SARAIVA, Renato. Veja como a lei da terceirização vai mudar a vida do trabalhador. Disponível em: <http://economia.ig.com.br/2015-04-09/veja-como-a-lei-da-terceirizacao-vai-mudar-a-vida-do-trabalhador.html>.

SARAIVA, Renato. Lei da terceirização: posição contrária. Jornal Carta Forense, 2 jun. 2015. Disponível em: <http://cartaforense.com.br/conteudo/artigos/lei-da-terceirizacao--posicao-contraria/15392>. Acesso em: 6 nov. 2015.

SARMENTO, George. Danos morais. Coordenação Edison Mougenot Bonfim. 1.ed. São Paulo: Saraiva, 2009. (Coleção prática de direito, v. 9).

SOUTO MAIOR, Jorge Luiz. PL 4.330/04: maldade explícita e ilusão. Disponível em: <http://blogdaboitempo.com.br/2015/04/06/pl-4-33094-maldade-explicita-e-ilusao>. Acesso em: 5 nov. 2015. 
SOUTO MAIOR, J. L.; MENDES, R.; SEVERO, V. S. Dumping social nas relaçôes de trabalho. São Paulo: LTR, 2012.

SOUTO MAIOR, Jorge Luiz. O dano social e sua reparação. Revista LTR, vol. 71, n. 11, p. $71-11 / 1.317$, nov. 2007.

STOCO, Rui. Tratado de responsabilidade civil: doutrina e jurisprudência. 8. ed. São Paulo: Ed. Revista dos Tribunais, 2011.

SUPREME Court of The United States no 94-986 - BMW of North America, INC., PETITIONER, $v$. IRA GORE, Jr., May 20, 1996.

TOFFLER, Alvin. A terceira onda. Rio de Janeiro: Record, 1980. p. 27-45.

VIEIRA, Maria Margareth Garcia. A globalização e as relaçóes de trabalho. Curitiba: Juruá, 2002.

ZENNI, Alessandro Severino Valler; PARRON, Stênio Ferreira. Por uma filosofia da pessoa no direito do trabalho. Revista Juridica Cesumar-Mestrado, v. 12, n. 1, p. 22, 2012. 